\title{
LOS EDUCADORES FRENTE A LAS INVESTIGACIONES DEL NIÑO ${ }^{1}$
}

\section{Educators front child research}

\author{
María Paulina Mejía Correa², Sofía Fernández Fuente ${ }^{3}$
}

\section{Recibido: 2019-03-28 Aceptado: 2019-04-21}

Resumen: Este artículo presenta una de las categorías construidas en la investigación titulada La pulsión de saber en la obra de Sigmund Freud. En él se presentan algunas posiciones de los educadores frente a las primeras investigaciones de los niños relativas al origen, la sexualidad y la muerte. Dentro de estas posiciones se destacan el engańo, la sofocación violenta y el esclarecimiento, las cuales tienen diversas consecuencias en la relación que el niño tendrá a futuro con el saber. En tal sentido, lo que acontezca en el vínculo educativo le podrá permitir a la pulsión o no tener como uno de sus objetos el saber.

Palabras clave: Engańo, esclarecimiento, posiciones de los educadores, pulsión de saber, represión violenta.

\begin{abstract}
This article presents one of the categories built in the research entitled The Drive of Knowledge in the work of Sigmund Freud. It presents some positions of educators in the face of early investigations by children on origin, sexuality and death. Among these positions are deception, violent suffocation and enlightenment, which have various consequences in the future relationship the child will have with knowledge. In this sense, what happens in the educational link may allow the pulsing or not to have as one of its objects knowledge.
\end{abstract}

Keywords: Deception, enlightenment, positions of educators, pulse of knowledge, violent repression.
Para citar este artículo en APA: Mejía, C y Fernández, S. (2019). Los educadores frente a las investigaciones del niño. Revista de Psicología Universidad de Antioquia, 11(1), 137175. DOI: https://doi.org/10.17533/ udea.rp.v11n1a06
Artículo derivado del proyecto de investigación "La pulsión de saber en la obra de Sigmund Freud", financiado por el CODI de la Universidad de Antioquia.

2 Psicóloga clínica Universidad San Buenaventura, Medellín. Magíster y Doctora en Ciencias Sociales y Humanas (Línea psicoanálisis y problemas contemporáneos), Universidad de Antioquia, Colombia. Profesora Facultad de Educación. Correo: paulina.mejia@udea.edu.co; https://orcid.org/00000002-7470-7872.

3 Psicóloga Universidad de Antioquia. Magister en Ciencias Sociales (énfasis en psicoanálisis, cultura y vínculo social). Profesora Universidad de Antioquia e Institución universitaria de Envigado. https://orcid.org/000002-4436-7459 


\section{Introducción}

El grupo de investigación Conversaciones entre pedagogía y psicoanálisis, realizó la investigación intitulada 'La relación maestro-alumno desde el psicoanálisis. Un estado del arte en Colombia' (Mejía, Flórez, Fernández, Cortés y Toro, 2009). Con ella se proponía visibilizar las publicaciones realizadas en Colombia que desde el psicoanálisis han contribuido en la comprensión de la relación maestro-alumno, en el período comprendido entre 1986 y 2006.

Esta investigación permitió identificar una serie de nociones y conceptos psicoanalíticos utilizados por múltiples autores en el abordaje de problemáticas educativas, entre ellos se encuentran: inconsciente, transferencia, sexualidad y deseo de saber. Particularmente, una de las nociones con más problemas en su tratamiento en los escritos analizados es el deseo de saber. Miremos algunas inquietudes que de su análisis se derivan:

a) Sobre el maestro recaen una serie de imperativos, uno de ellos es que él debe reconocer su deseo y alentar el deseo de sus alumnos, pero paradójicamente se afirma que dicho deseo es inconsciente.

b) La noción deseo de saber se equipara con palabras como creación, deseo de enseñar, pasión, motivación y amor al saber. Nos preguntamos si es posible sostener esta sinonimia en el marco de la teoría que le dio lugar a la noción.

c) Se le asignan al maestro unas funciones respecto al deseo como, por ejemplo, “[...] mostrarle al estudiante que el paraíso está perdido para siempre” (Mejía et al., 2009, p. 45), para alentar su deseo de saber. Pero ¿en qué consiste esta tarea y por qué esta impacta el deseo del estudiante?

d) También se afirma que el maestro debe lograr "[...] vincular el deseo al placer, restándole con ello posibilidades al goce [...]" en cada estudiante (p. 45). De ello una pregunta: ¿̨el deseo se vincula al placer o es el placer un derivado lógico del deseo?

e) De igual modo, se dice que "[...] es la falta la que moviliza la pasión del saber” (p. 46), sin embargo, no explicitan de qué falta se trata. 
Estas son algunas de las preguntas que nos invitaron a trabajar la noción deseo de saber desde el campo que le dio su origen: el psicoanálisis. Trabajo que permite delimitar los alcances y límites de dicha noción para pensar problemas educativos. Para tal fin, definimos como propósito de este estudio analizar las significaciones que tiene la noción deseo de saber en la obra de Freud, el cual nos permitió construir cuatro categorías, ellas son: enigmas fundantes de la pulsión de saber; los educadores frente a las investigaciones de los niños; los componentes de la pulsión de saber; y la pulsión de saber: entre la repetición y la invención o las metáforas de unas posiciones frente al saber. En este artículo presentaremos una de ellas: los educadores frente a las investigaciones de los niños.

\section{Metodología}

La presente investigación se enmarca en el paradigma cualitativo, el cual, en los términos de Strauss y Corbin (2002), permite conocer la realidad social y estudiarla. O, en palabras de Álvarez-Gayou (2012), la investigación cualitativa busca "[...] explicar y comprender las interacciones y significados [...]" (p. 41). Esta modalidad de comprensión de la realidad supone, pues, acceder al mundo de las representaciones bajo sus diversas expresiones. En tal sentido, los datos a estudiar pueden venir de fuentes como películas, entrevistas, documentos, observaciones, entre otros. Es así como la investigación cualitativa busca producir significados a partir de las relaciones encontradas entre las representaciones que se logren develar en las fuentes.

De la misma manera, la presente investigación se inscribe en el marco referencial de la hermenéutica, la cual se define como: [...] la teoría y la práctica de la interpretación [...]" (Álvarez-Gayou, 2012, p. 80). Al respecto Wilhelm Dilthey propone "[...] la hermenéutica textual como una metodología de las ciencias sociales [...]” (citado por Álvarez-Gayou, 2012, p. 80).

$\mathrm{Y}$ en este marco, nos apoyamos para la interpretación de los textos de Freud en una propuesta de análisis que desarrolla Juan Fernando Pérez en su artículo Elementos para una teoría de la lectura (1997). Él propone tres modalidades en la interpretación de los textos, las cuales se pueden conjugar si así lo requieren los propósitos del lector. 
En tal sentido, el presente estudio se sirve de la lectura intratextual, intertextual y extratextual. La lectura intratextual le exige al lector producir significados sólo a partir de las relaciones que se establezcan entre los significantes que provee el escrito analizado. Ello supone poner en suspenso los saberes previos, para dejar que sea el texto mismo el que devele sus significados. De esta lectura se extraen las precategorías de la investigación, es decir, aquello que insiste en los modos como se comprende la noción de deseo de saber. La lectura intertextual permite poner en relación las precategorías para agruparlas según sus afinidades y así darles lugar a las categorías. El tercer momento será la lectura extratextual, la cual permite poner en diálogo los hallazgos con autores que permitan afinar los modos de nombrar lo encontrado.

Ahora bien, la presente investigación tiene como fuente principal las obras completas de Freud editadas por Amorrortu, debido a que esta traducción cuenta con un gran reconocimiento en la comunidad académica latina, fundamentalmente por el modo como fue hecha la traducción. El mismo Etcheverry, editor de la obra, afirma que la traducción que realizaron del alemán al español fue comparada con la realizada por J. Strachey, quien la hizo del alemán al inglés. De igual modo, Amorrortu compara su traducción con las realizadas por López Ballesteros y Ludovico Rosenthal para realizar "[...] una suerte de encuesta terminológica [...]" (Freud, 1979a, p. 2). A su vez, Amorrortu busca sostener los sentidos asignados por Freud a los conceptos capitales del psicoanálisis, y, para ello, se sirve de las concepciones antropológicas y filosóficas predominantes en el contexto alemán del siglo XIX (Freud, 1979a).

Dicho lo anterior es menester hacer una aclaración. Cuando Freud alude a la palabra deseo lo hace en algunas obras como La interpretación de los sueños (1979b) y Psicopatología de la vida cotidiana (1979c), para hacer alusión a representaciones que habitan en el inconsciente luego de ser desalojadas de la conciencia por la represión. Esos deseos, que luego de ser reprimidos se vuelven chocantes a la conciencia, en lo sucesivo, pulsan por salir, pero al encontrarse con la resistencia deben inventarse vías encubiertas para manifestarse, estas son las formaciones del inconsciente: sueños, actos fallidos, olvidos, síntomas, chiste y lapsus. Formaciones que cuando se exteriorizan producen en el sujeto un extrañamiento, es decir, él no se reconoce en ellas; por lo tanto, 
sus contenidos no logran asociarse a la conciencia. Lo anterior nos permitió concluir con Freud que el sujeto no quiere saber sobre lo que lo habita en lo inconsciente.

Freud también nos propone otra relación al saber, ya no del orden de lo que se evita sino del orden de lo que se busca. Así, Freud utiliza la palabra apetito de saber cuando nos habla del pequeño investigador, quien busca desentrañar algunos enigmas que lo incomodan. Búsqueda de unos saberes relativos a lo que él significa en términos amorosos para sus padres, sobre la diferencia sexual anatómica y sobre el intercambio sexual de sus padres (1979d). Y es en este punto en el cual Freud nos habla del pequeño investigador en tanto se pregunta, construye conjeturas y categorías para intentar responderse esos enigmas.

Posteriormente, en una adición que hace Freud a Los tres ensayos de teoría sexual (1979d), nombra este apetito como pulsión de saber o pulsión de investigar. Pero, esta sinonimia no es inocente. Digamos que el apetito despierta apuntalado en el ámbito del autoerotismo y el narcisismo, algo así como al servicio de sí mismo y no del mundo. Es por ello que quizás Freud introduce la palabra pulsión asociada al saber, como un primer momento lógico por el que transita el pequeño investigador, cuando aún la pulsión no ha sido atravesada por la sublimación. Es decir, cuando aún las investigaciones del pequeño no se han puesto al servicio de la cultura. Tarea posterior, fruto de la represión, y de la cual Freud también nos da noticia cuando alude a la actividad investigadora del adulto, como es el caso de Leonardo Da Vinci (1979h).

Por consiguiente, conservamos la expresión de Freud pulsión de saber, en el desarrollo de la presente investigación.

\section{Consideraciones éticas}

De acuerdo con el Ministerio de Salud de la República de Colombia, en la Resolución número 8430 de 1993, y apoyados en el Artículo 11, podemos afirmar que la presente investigación es sin riesgo, en tanto es un estudio que emplean técnicas de investigación documental.

De acuerdo con ello, esta investigación tuvo en cuenta las siguientes consideraciones éticas. En primer lugar, elegir una traducción de la obra de Freud 
reconocida por la comunidad académica. En segundo lugar, elegir un método de análisis de texto que nos permitiera una interpretación lo más próxima posible a los significados que el texto provee. De igual modo, se tenían sesiones de trabajo en las cuales se ponía en común el análisis que hacía cada investigador y si era preciso todos leíamos el mismo texto para acordar los significados. Tuvimos también una asesoría con la Doctora Graciela Frigerioº ${ }^{3}$, con el fin de cuidar nuestro método de análisis. Y, por último, un tercer aspecto ético que tuvimos en cuenta fue el cuidar los derechos de autor, para lo cual se hacían las citas ajustados a las Normas APA Gta versión.

\section{Resultados}

En el presente artículo se da cuenta de una de las categorías construidas luego del análisis de los textos de Sigmund Freud que hacen alusión a la noción pulsión de saber o sus equivalentes: apetito de saber y pulsión de investigar. Esta categoría desarrolla algunas posiciones de los educadores frente a las investigaciones de los nińos y sus posibles consecuencias.

El recién nacido llega sin un ropaje simbólico que lo ampare y por ello requiere que los primeros otros lo interpreten, es decir, le den un lugar simbólico. Y si él es interpretado, él a su vez se vuelve un intérprete. En este sentido el niño lee las palabras, los silencios, las ausencias, las contradicciones del otro, solicita saber, no como un sujeto epistémico, sino como un sujeto tomado por preguntas que lo conciernen en lo más íntimo. Vemos entonces a un niño que al entrar en la estructura del lenguaje se enfrenta en adelante a los misterios de su concepción, así como al de su sexo. Y en este sentido, el lugar de los educadores es decisivo en la relación del niño con el saber. O como bien lo enuncia Frigerio: “Toda relación de saber y toda relación con el saber [...] está siempre inscripta en una trama en la que está siempre presente el más de uno en el corazón mismo de la mismidad (2010, p. 5).

El niño interpreta a los otros de múltiples maneras y les transmite de diferentes formas sus conjeturas, como quien quiere poner a prueba sus cons-

3 Doctora en educación, de la Universidad Paris VIII. Directora del doctorado en educación de la Universidad Litoral de Santa Fe, Argentina. 
trucciones ante quien se supone sabe. Sin embargo, en ese camino el pequeño puede encontrar múltiples posiciones en los educadores frente a sus investigaciones, posiciones que o bien le ayudan o, por el contrario, lo extravían en su relación con el saber. Freud advierte en su texto Sobre Psicología del colegial $(1979 j)$, sobre las consecuencias que tiene el vínculo con el educador en la relación al saber que construye el sujeto.

Nos dirá Freud en el texto El esclarecimiento sexual del niño (1979e) que los educadores, se refiere con ello a los padres y a los maestros, ante las preguntas que les hacen los niños pueden responder con tres posiciones: engaños, represión violenta o el esclarecimiento de aquello que los inquieta. Posiciones que tienen diversas consecuencias en la relación del niño con el saber, consecuencias que, digámoslo de una vez, o bien disminuyen o bien alimentan su placer de saber y crear.

Sobre la primera posición, el engañar, refiere Freud (1979e) que ello ocurre porque el educador subestima la capacidad de comprensión del nińo frente a los enigmas que le preocupan. Subestimar es restarle valor o no reconocer la existencia de un interés en los nińos por preguntas como la sexualidad, el origen y la muerte, preguntas a las que alude Freud en el texto Tres ensayos de teoría sexual (1979d) y Sobre las teorías sexuales infantiles (1979f).

Se precisaría entonces por parte del educador que deposite confianza en el niño, en su capacidad de pensar y aprender saberes, saberes que en este caso le incumben en lo más íntimo. Se requiere una disposición para compartir, no solo lo sabido sino también lo ignorado, como nos dice Frigerio (2010, pp. 9-10). Así las cosas, no se trata de un educador que todo lo responde, sino de un educador que aloja al niño, lo escucha y le permite avanzar en sus investigaciones con los límites que ella supone. Hablamos de límites en el sentido en que no todo se podrá saber, pero no por ello al niño se le debe subestimar en sus búsquedas.

Advierte Freud $(1979 e$, ) que "no es sino la vulgar mojigatería y la propia mala conciencia en asuntos sexuales lo que mueve a los adultos a usar de esos «tapujos» con los niños; [...]" (p. 116). De igual modo, afirma que puede haber en los adultos cierta ignorancia teórica que le hace suponer la inexistencia de la pulsión sexual en los niños. 
La vulgar mojigatería, la mala conciencia y los prejuicios del educador le impiden responder a la solicitud de compañía y orientación que le hace el niño para avanzar en el camino de comprender algo de lo que le pasa; y, a su vez, lo protegen de lo incierto que nos presentan los niños con sus preguntas sobre el origen, la sexualidad y la muerte. Así, la misma naturaleza de estas preguntas parece que favorecen el que se tejan alrededor de ellas prejuicios como respuestas anticipadas que taponan su condición enigmática. El prejuicio, entonces, también elimina la posibilidad del más de uno, la posibilidad de un vínculo educativo que acompañe al pequeño en sus indagaciones, y también "influye, condiciona, hace pantalla, impide el encuentro con el otro (con lo enigmático del otro) y con el saber (con lo enigmático de lo por-conocer)" (Frigerio, 2010, p. 16).

El engañar, bien porque se subestima la capacidad de comprensión del niño o por los prejuicios del educador, deriva en una serie de consecuencias para el pequeño. Refiere Freud que en la mayoría de los casos los niños se extravían y equivocan en la construcción de sus respuestas.

Así, cuando los educadores escatiman cierto conocimiento al niño, es decir, la posibilidad de ponerle palabras a sus preguntas, hacer conjeturas, hipótesis, cuando no se disponen a escucharlo, lo extravían en su investigación, exacerban sus divagaciones y construcciones imaginarias ante la ausencia de otro que le ayude a despejar, así sea parcialmente, sus preguntas (Freud, 1979e, p. 120). Es como si lo desorientaran en sus indagaciones, lanzándolo por caminos que le pueden generar angustias evitables.

Otro de los efectos del engaño por parte de los educadores es la desconfianza que ello le suscita al niño y el inicio de una autonomía intelectual; es decir, de un pensar sin contar con el otro (Freud, 1979h, p. 73). Digamos que es una autonomía intelectual fruto de una falta de credulidad, una autonomía que habla de cierta soledad a la que se ve abocado el niño cuando no encuentra a alguien que lo escuche y le de valor a sus investigaciones. Este desprecio por parte del adulto hacia las investigaciones del niño contribuye, pues, a que se martirice en secreto con sus preguntas y construya una serie de soluciones con "inexactitudes grotescas" y con "el sello de lo cruel y lo asqueroso" (Freud, 1979e, p. 120). 
Así las cosas, en el engaño el niño no deja de indagar, él se sigue preguntando. Entonces, lo que puede ser un esclarecimiento frente a las primeras preguntas de los niños puede tomar otros caminos:

Las respuestas usuales en la crianza de los niños menoscaban su honesta pulsión de investigar, y casi siempre tienen como efecto conmover por primera vez su confianza en sus progenitores; a partir de ese momento, en la mayoría de los casos empiezan a desconfiar de los adultos y a mantenerles secretos sus intereses más íntimos (1979e, p. 119).

Vemos, entonces, cómo es de importante el otro en las primeras indagaciones del niño, y la trascendencia de la posición que el educador asuma frente a los caminos de la pulsión de saber. En este caso, si se subestiman las investigaciones infantiles, el niño no confiará en el educador y, en consecuencia, preferirá guardar en secreto sus investigaciones y buscar otras vías para construir respuestas. Observamos pues que allí donde falta el otro en las primeras indagaciones de los niños puede suceder que se exacerbe lo imaginario, cuyo contenido las más de las veces se tińe de lo cruel.

Otra de las posiciones del educador es el amedrentamiento o sofocación violenta de la pulsión de saber del niño. La intimidación a las preguntas se puede dar a través del discurso religioso, la amenaza, el castigo físico o palabras que lo degradan, lo que puede acarrearle al nińo un sentimiento de culpa (Freud, 1979 e, p. 120).

Esta es otra cara del desprecio del educador hacia las investigaciones infantiles, solo que en este caso reacciona con una sofocación violenta de los intereses del niño. Lo paradójico es que esta sofocación violenta no extingue las pulsiones, sino que las reprime, contribuyendo a que se gesten en el niño serios problemas con el saber (Freud, 1979i, p. 192). La severidad, es, por tanto, una de esas reacciones que contribuye a 'apagar' la pulsión de saber, es decir, a no querer saber nada sobre aquello que lo inquieta, lo que en consecuencia afectará la posibilidad de que el niño sublime a partir de lo que en principio ocupó su apetito de saber. La sublimación supone que el saber se convierte en objeto de la pulsión, y gracias a ello el niño podrá encontrar satisfacción en actividades del lado de la investigación. 
Una tercera posición del educador, por lo demás la menos frecuente, es la del esclarecimiento. Freud habla de esta posición a propósito de una consulta que le hace el doctor M. Furth, quien le pide que escriba un artículo para que dilucide cómo debe impartirse la educación sexual a los nińos. Freud da respuesta a la solicitud: "Debo, pues, responderles a estas cuestiones: si en general es lícito proporcionar a los nińos esclarecimiento sobre los hechos de la vida genésica, a qué edad convendría hacerlo y de qué manera" (1979e, p. 115). Inicia su artículo con una serie de preguntas que buscan comprender cuáles son las creencias que impiden al educador ayudarles a los niños en sus investigaciones que, en este caso, son sobre la sexualidad. Algunas de esas creencias es el suponer que la educación puede despertar prematuramente la sexualidad; o que mediante el encubrimiento se puede detener la pulsión sexual hasta que sea lícito socialmente que ella se exprese; o esperar que tras su ocultamiento se lograra que los niños "juzguen inferior y abominable todo lo sexual" (1979e, pp. 115-116).

Según Freud, esos propósitos son absurdos y para refutarlos hace referencia a la carta del filántropo Multatuli ${ }^{4}$ que, en esencia, sostiene que la pureza de los niños no se preserva mediante la ignorancia; por el contrario, entre más se oculte algo a los niños, más maliciarán la verdad; además, para este autor, es imposible preservar la ignorancia del nińo, pues al entrar en contacto con otros tendrá la información que los adultos le han negado.

Freud sostiene que las investigaciones del niño, las cuales se manifiestan desde muy temprano, se pueden resolver con la ayuda del educador mediante un sutil esclarecimiento. Sin embargo, el autor indica que la tan frecuente ceguera de los padres hacia los intereses de los niños afecta dicho esclarecimiento (1979e, p. 117).

Sostiene Freud (1979e, p. 120) que casi todos los autores que han escrito sobre el esclarecimiento sexual están a favor de este, pero la dificultad ha estado en definir cómo y cuándo. La tendencia en su época fue aplazar el mayor tiempo posible dicho esclarecimiento y cuando se hacía ya era tarde y con respuesta a medias.

4 Multatuli es el seudónimo de un conocido escritor holandés, E. D. Dekker (1820-1887) y es citado por Freud en el texto El esclarecimiento sexual del niño de 1907. 
Sobre el modo de hacerlo Freud afirma que es importante que los niños no sientan que hay un encubrimiento mayor en torno a la sexualidad que sobre cualquier otro tema que también les es desconocido o que no comprende. Sugiere que los temas sexuales sean tratados:

[...] en un pie de igualdad con todas las otras cosas dignas de ser conocidas. Principalmente, es misión de la escuela el traerlo a cuento, introducir en las enseñanzas sobre el mundo animal los grandes hechos de la reproducción en su significatividad y, al mismo tiempo, insistir en que el ser humano comparte con los animales superiores todo lo esencial de su organización. (Freud, 1979e, pp. 120-121)

En tal sentido, si los educadores asumen en condiciones de igualdad el tema de la sexualidad con cualquier otra área del conocimiento y tienen como misión introducir la sexualidad sin tapujos; $y$, adicional a esto, si en la familia no se le atemoriza o inhibe su pensamiento y no se reprime la pulsión de saber al niño, se le posibilitará responder en lo que sea posible las inquietudes, los temas que le generan enigma, siendo la sexualidad uno más de ellos.

Frente a la pregunta de cuándo es el momento propicio para el esclarecimiento sobre "las relaciones específicamente humanas de la vida sexual y la indicación de su significado social" (1979e, p. 121), Freud propone que ello debe darse en la escuela primaria y antes de llegar a los 10 ańos. En tal sentido, tanto en la escuela como en el hogar, se trata de permitirle al niño una dinámica de pensamiento sin temores y un esclarecimiento sexual de la mano de los educadores, que le permita elaborar sus propias construcciones, sin distorsiones que más tarde lo lleven a juzgar la sexualidad como algo inferior o detestable.

Freud se sirve del caso del pequeño Hans $(1979 g)$ de 4 años para enseñarnos que sus padres no inhibieron la investigación sexual del niño, lo cual le posibilitó que a temprana edad construyera múltiples categorías para resolver sus preguntas por la sexualidad.

Freud (1979e) sostiene que el esclarecimiento sobre la sexualidad debe progresar por etapas y no interrumpirse nunca; ello, a su juicio, protegerá al niño de ciertos peligros existentes (p. 121); peligros, quizás como los abusos sexuales y la exacerbación de construcciones crueles y grotescas como parte de las teorías que construyen sobre la sexualidad. 
No solo el saber sobre la sexualidad se da con tapujos, podríamos afirmar que también se silencia el tema de la muerte y del origen en la educación de los niños; así, es común que se silencien sus preguntas con respuestas religiosas. Sabemos que la religión es un sistema de pensamiento creado por la humanidad para hacerle frente a la muerte, pero aquí queremos insistir en la posibilidad que un educador le puede ofrecer al niño de hablar, de expresar sus angustias, de formular sus preguntas, hipótesis y conjeturas sin que ello sea reprimido con los prejuicios de los educadores.

Como hemos visto en este recorrido, el niño precisa del más de uno, precisa de un educador que lo acompañe, que no lo amedrente, para que no afecte la apertura de caminos que le hagan posible convertir el saber en objeto de la pulsión.

Por el contrario, si el niño es engañado, desestimado o sofocado violentamente en la investigación por el educador, se silenciará, abandonará sus indagaciones y se afectará en consecuencia su relación con el saber. No obstante, es menester aclarar que no se aboga por un educador que responda todas las preguntas, pues él tampoco tiene todas las respuestas. Se trata de un educador que pueda escuchar e incluso permitirle al niño cierta soledad creativa, es decir, que le posibilite realizar sus investigaciones y con ella sus preguntas, hipótesis y conjeturas sin que obtenga como respuesta el engaño o la sofocación violenta de su pulsión de saber. Se trata pues de dejar que el niño incluso dude de las respuestas de los educadores. Nos dice Piera Aulagnier (1980) que:

Este "momento de duda" es esencial para la estructura del Yo y para la disposición de una actividad de pensamiento que acepte la supremacía del principio de realidad, a pesar de una pérdida de placer, compensada, es cierto, por otro placer vinculado con una primera conquista de una autonomía de pensamiento parcial. (p. 64)

Este momento de duda le permitirá al niño separarse de la voz idealizada de sus padres y optar por la construcción de sus juicios de verdad. Independencia de pensamiento muy importante en tanto supone una desalienación de los otros, una capacidad de construir sus respuestas más allá de las de sus educadores. Nos dice Piera Aulagnier (1980): “El jefe carismático puede estar 
bastante catectizado e idealizado para que el juicio de verdad sea una función exclusiva de la catectización de la instancia idealizada" (p. 66). Así pues, cuando el sujeto tiene muy idealizado al otro, el principio de realidad se desvanecerá como rector de sus juicios de verdad.

De igual modo, hay que matizar con Freud los límites y alcances de la educación en lo que tiene que ver con la investigación de los niños. En las Conferencias de introducción al psicoanálisis, (1979k) nos encontramos con que el niño por factores de orden estructural no puede saberlo todo sobre lo que se pregunta con relación a su origen, la sexualidad y la muerte; así las cosas, nada lo librará de la represión y de los traumas derivados precisamente de lo imposible de saber. Así, ese imposible nos hace sufrir, pero, a su vez se constituye en motor de la investigación. Nos dirá Freud (1979k, p. 136) que estamos frente a un niño inacabado, condición que lo expone al trauma, en tanto su yo no cuenta con recursos para defenderse de los afectos que se producen por múltiples impresiones. Por lo cual no le queda otro recurso que la represión de aquello que no logró comprender, de aquello que no logró saber; así la represión es su defensa frente a aquello que lo perturba. Pero eso no sabido y olvidado, podrá a lo sumo constituirse en motor para futuras investigaciones por la vía de la sublimación, las cuales serán circunloquios de las preguntas no resueltas.

\section{Discusión y conclusiones}

Este camino nos ha permitido dilucidar que la relación del niño con el saber es afectada por las posiciones que los educadores asumieron frente a sus primeras investigaciones. En contraposición al engaño y a la sofocación violenta como respuestas de los adultos frente a las indagaciones de los niños, Freud recomienda el esclarecimiento, el cual supone permitirle al pequeño hacer sus indagaciones, sus conjeturas y proporcionarle respuestas que eviten construcciones imaginarias y grotescas para responderse sus primeros enigmas. Sin embargo, Freud advierte que este esclarecimiento no salvará al niño de lo traumático que supone estar en el mundo del lenguaje, es decir, del encuentro con lo innombrable y con lo que de ello se deriva en términos subjetivos. Pero 
a pesar de lo innombrable, podemos concluir que el vínculo educativo es fundamental para posibilitar la apertura de caminos por el lado de la creación y la investigación. Caminos que le permiten a la pulsión derivarse en sublimación, y con ello encontrar placeres que hagan soportable la vida.

En la obra de Freud encontramos que la pulsión de investigar surge en el niño orientada por unas preguntas que lo conmueven en lo más íntimo, ellas son: el origen, la sexualidad y la muerte. Preguntas frente a las cuales él construye teorías con fragmentos que recoge de lo que los otros le transmiten y de lo que él recrea a través de sus interpretaciones. En tal sentido, el pequeño investigador solicita la compañía del otro para que le ayude en sus investigaciones. Una solicitud que puede tener diversas respuestas por parte de los educadores, las cuales tendrán consecuencias en la relación que a futuro tenga el niño con el saber cómo objeto de la pulsión.

Este estudio pone de presente, por tanto, que los niños solicitan un educador que los acompañe en sus indagaciones, los acompañe con sus saberes y sus no saberes, que sea un mediador frente a las teorías que él construye. No solicita un educador que todo lo sabe, pues, como lo advierte Freud, hay una autonomía intelectual que se logra en tanto el niño pueda construir sus juicios, basado más en el principio de realidad que en el amor que les profesa a los educadores.

Ahora bien, sabemos que el educador transmite, incluso más allá de lo que quiere, y el otro, en este caso el nińo, interpreta lo que le viene del otro también a su manera. Con ello advertimos que, si bien el vínculo educativo es necesario en las investigaciones del pequeño, no lo eximen de interpretaciones crueles y grotescas relativas a su origen, la sexualidad y la muerte.

De igual modo, esta investigación abre horizontes para nuevos estudios que podrían indagar los modos como hoy los niños se las arreglan con sus primeras investigaciones, pues sabemos que las teorías que construían en la época de Freud pueden distar mucho de las que ellos hoy construyen. Nos referimos a que en este tiempo los nińos acceden rápidamente a información por medios digitales y de ello, seguramente, obtienen múltiples respuestas a sus preguntas.

También sería propicio saber cómo están respondiendo hoy los educadores a las novedades que les presentan los niños; por ejemplo, cómo responden 
ellos frente al exceso de información que tienen los niños sobre la sexualidad. Nos preguntamos si lo hacen también con engaños, sofocación violenta o acuden al acompañamiento en las investigaciones de los niños. Estas dos perspectivas se abren para futuras investigaciones luego de realizar el presente estudio.

Para finalizar, como ya se advirtió, esta investigación se apoyó en la traducción que sobre la obra de Sigmund Freud realizó la Editorial Amorrortu. Ello plantea una limitación, pues sabemos que existen otras traducciones como la de Strachey y Ballesteros, las cuales pueden ingresar novedades al estudio sobre la pulsión de saber.

\section{Referencias}

Álvarez-Gayou, J. (2012). Cómo hacer investigación cualitativa. Fundamentos y metodología. México: Paidós.

Aulagnier, P. (1980). Los destinos del placer. Alienación, amor, pasión. Madrid, España: Ediciones Pretel.

Freud, S. (1979a). Sobre la versión castellana. En Autor. Obras completas. Buenos Aires, Argentina: Amorrortu editores.

Freud, S. (1979b). La interpretación de los sueńos (1900). Primera parte. En Autor. Obras completas. Tomo VI. Buenos Aires, Argentina: Amorrortu editores.

Freud, S. (1979c). Psicopatología de la vida cotidiana. (1901). En Autor. Obras completas. Tomo VI. Buenos Aires, Argentina: Amorrortu editores.

Freud, S. (1979d). Tres ensayos de teoría sexual (1905). En Autor. Obras completas. Tomo VII (pp. 109-224). Buenos Aires, Argentina: Amorrortu editores.

Freud, S. (1979e). El esclarecimiento sexual del niño (Carta abierta al doctor M. Fürst) (1907). En Autor. Obras completas, Tomo IX. Buenos Aires, Argentina: Amorrortu editores.

Freud, S. (1979f). Sobre las teorías sexuales infantiles (1908). En Autor. Obras completas. Tomo IX (pp. 183-202). Buenos Aires, Argentina: Amorrortu editores.

Freud, S. (1979g). Análisis de la fobia de un niño de cinco años (1909). En Autor. Obras completas. Tomo IX (pp. 1-118). Buenos Aires, Argentina: Amorrortu editores. 
Freud, S. (1979h). Un recuerdo infantil de Leonardo da Vinci (1910). En Autor. Obras completas. Tomo XI (pp. 53-128). Buenos Aires, Argentina: Amorrortu editores.

Freud, S. (1979i). El interés por el psicoanálisis (1913). En Autor. Obras completas. Tomo XIII (pp. 165-192). Buenos Aires, Argentina: Amorrortu editores.

Freud, S. (1979j). Sobre la psicología del colegial (1914). En Autor. Obras completas. Tomo XIII (pp. 243-250). Buenos Aires, Argentina: Amorrortu.

Freud, S. (1979k). 34a. Conferencia: Esclarecimientos, aplicaciones, orientaciones (1932-1936). En Autor. Obras completas. Tomo XVI. (pp. 126-145). Buenos Aires, Argentina: Amorrortu editores.

Frigerio, G. (2010). Curioseando (saberes e ignorancias). En Autor. Saberes alterados. Buenos Aires, Argentina: El Estante Editores.

Mejía, M. P, Flórez, S., Fernández, S., Cortés M., y Toro G. (2009). La relación maestra-alumno desde el psicoanálisis. Un estado del arte en Colombia. Separata Revista Educación y pedagogía. Medellín, Colombia: Facultad de Educación.

Pérez, J. (1997). Elementos para una teoría de la lectura. En Autor. Utopía Siglo XXI (pp. 111-126). Medellín, Colombia: Universidad de Antioquia, Facultad de Ciencias Sociales y Humanas.

Strauss, A., y Corbin, J. (2002). Bases de la investigación cualitativa. Técnicas y procedimientos para desarrollar la teoría fundamentada. Medellín, Colombia: Editorial Universidad de Antioquia. 